\title{
An analysis of the collection 5 MODIS over-ocean aerosol optical depth product for its implication in aerosol assimilation
}

\author{
Y. Shi ${ }^{1}$, J. Zhang ${ }^{1}$, J. S. Reid ${ }^{2}$, B. Holben ${ }^{3}$, E. J. Hyer ${ }^{2}$, and C. Curtis ${ }^{2}$ \\ ${ }^{1}$ Department of Atmospheric Science, University of North Dakota, Grand Folks, ND, USA \\ ${ }^{2}$ Marine Meteorology Division, Naval Research Laboratory, Monterey, CA, USA \\ ${ }^{3}$ NASA Goddard Space Flight Center, Greenbelt, MD, USA
}

Received: 1 June 2010 - Published in Atmos. Chem. Phys. Discuss.: 26 August 2010

Revised: 24 November 2010 - Accepted: 25 November 2010 - Published: 19 January 2011

\begin{abstract}
As an update to our previous use of the collection 4 Moderate Resolution Imaging Spectroradiometer (MODIS) over-ocean aerosol optical depth (AOD) data, we examined ten years of Terra and eight years of Aqua collection 5 data for its potential usage in aerosol assimilation. Uncertainties in the over-ocean MODIS AOD were studied as functions of observing conditions, such as surface characteristics, aerosol optical properties, and cloud artifacts. Empirical corrections and quality assurance procedures were developed and compared to collection 4 data. After applying these procedures, the Root-Mean-Square-Error (RMSE) in the MODIS Terra and Aqua AOD are reduced by $30 \%$ and 10-20\%, respectively, with respect to AERONET data. Ten years of Terra and eight years of Aqua quality-assured level 3 MODIS over-ocean aerosol products were produced. The newly developed MODIS over-ocean aerosol products will be used in operational aerosol assimilation and aerosol climatology studies, as well as other research based on MODIS products.
\end{abstract}

\section{Introduction}

Recent studies have shown that the assimilation of satellite aerosol products, such as the near real time Moderate Resolution Imaging Spectroradiometer (MODIS) aerosol optical depth product, can improve aerosol analyses and forecasts (e.g. Zhang et al., 2008). However, biases and uncertainties exist in satellite aerosol data due to the complications inherent to retrieval processes and varying observational condi-

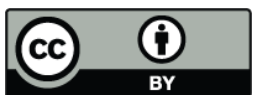

Correspondence to: J. Zhang

(jzhang@atmos.und.edu) tions (e.g. Zhang and Reid, 2006; Liu and Mishchenko, 2008 and Kahn et al., 2009). The impact of product uncertainty is application specific. In the area of data assimilation for aerosol forecasting, the tightest tolerances are required, because any noise or systematic high bias in the product will propagate through the analysis to the forecasting cycle.

Products from the MODIS sensors can provide high spatial and spectral resolution aerosol data with observations twice a day that cover most of the planet. Retrievals are possible over global oceans and most vegetated regions. MODIS data is also easily accessible in near real time. These advantages make MODIS one of the most popular satellite aerosol products in current aerosol research for numerous applications. To employ MODIS data in an aerosol forecasting system, Zhang and Reid (2006) created a series of procedures to remove outliers and reduce bias in MODIS Collection 4 (C4), level 2, over-ocean, aerosol products. The data performances for the year 2005 were examined as functions of the main sources of uncertainties, such as boundary conditions, cloud contaminations, and aerosol microphysics. Empirical studies and quality control procedures were applied to create quality assured MODIS level 3 aerosol products. The newly generated MODIS aerosol products from Zhang and Reid (2006) are specifically made for aerosol data assimilation and forecasting where they have been successfully used (e.g. Zhang et al., 2008). MODIS AOD data assimilation is now operational at the Fleet Numerical Meteorology and Oceanography Center (FNMOC) to aid Navy Aerosol Analysis and Prediction System (NAAPS) forecasts.

However, after Zhang and Reid's study, the MODIS Collection 5 (C5), level 2, aerosol products have been distributed since 2007. Developers indicated very minor differences between C4 and C5 data over oceans (personal communication Robert Levy and Lorraine Remer, NASA Goddard SFC).

Published by Copernicus Publications on behalf of the European Geosciences Union. 
However, before C5 data could be incorporated into the operational data stream, it was necessary to verify the data for the specific purpose of data assimilation (Kahn et al., 2009) and re-evaluate the procedures developed for $\mathrm{C} 4$ for their potential to improve the MODIS C5 aerosol products. Instead of using only one year of data, this paper applies Zhang and Reid's methods to the C5 over-ocean aerosol data, using ten years of Terra and eight years of Aqua data to analyze the temporal performance differences between $\mathrm{C} 4$ and C5 MODIS products. After applying the empirical corrections and quality assurance procedures, the more robust new aerosol products were generated for the MODIS data for all the available time periods.

\section{Data}

The ground-based aerosol observations from the AErosol RObotic NETwork (AERONET) were used to validate MODIS satellite data. AERONET is a global network of Sun photometers that provides ground-based aerosol optical depth measurements and optical property retrievals (Holben et al., 1998). All available level 2.0 AOD data (cloud screened and quality assured), which has a reported uncertainty of approximately $0.01-0.02$ in AOD (wavelength dependent) due to calibration (e.g. Holben et al., 1998) were used. In order to evaluate satellite aerosol products, both MODIS Terra and Aqua satellite aerosol products were collocated with the ground-based AERONET data. To minimize the spatial and temporal difference between these data, pairs of AERONET Sun photometer data and MODIS aerosol retrievals were matched where the spatial distance between two observations were within $0.3^{\circ}$ (latitude/longitude) and the difference in observation times were within $+/-30 \mathrm{~min}$. AERONET data were averaged temporally within the onehour collocation time window. However, the satellite observations were not averaged spatially. Many previous studies used averaged satellite data and Sun photometer data to overcome the spatial and temporal differences between the two data sets (Remer et al., 2005; Kahn et al., 2009; Hsu et al., 2006). This approach is understandable considering the spatial and temporal differences between the observations. Integrated through the atmosphere column, AERONET provides point observations at a given time, whereas a satellite retrieval from passive sensors such as MODIS represents a column integrated two-dimensional spatial observation at a given time. Because of the different sampling methods, differences between the two types of observations can exist. However, in this study, in order to investigate the uncertainties in the satellite retrievals due to observing conditions at a pixel level, satellite data were not averaged.

Both AERONET and MODIS aerosol data at the $0.55 \mu \mathrm{m}$ spectral wavelength were used in this study, and discussions mentioned hereafter refer to the aerosol data at the $0.55 \mu \mathrm{m}$, unless specifically mentioned. Note that the AERONET data do not include observations at the $0.55 \mu \mathrm{m}$ spectral channel, and therefore, the AERONET observations from 0.50 and $0.67 \mu \mathrm{m}$ were used to estimate aerosol optical depth values at the $0.55 \mu \mathrm{m}$ based on the method by O'Neill et al., (2001).

As satellite over-ocean retrievals were used, only AERONET data from coastal or island sites were selected. Three collocated data sets were included in this study. (1) Terra MODIS C5 aerosol products and AERONET level 2.0 data from 2000 to 2008; (2) Aqua MODIS C5 aerosol products and the AERONET level 2.0 data from 2002 to 2008; and (3) MODIS Terra and Aqua C5 aerosol products and AERONET level 1.5 data for 2009 for independent validation efforts. The level 1.5 AERONET data were used for 2009 because the complete set of the quality assured level 2.0 AERONET data were not readily available yet. All three data sets were also collocated with the near surface wind speed data from the Navy Operational Global Analysis and Prediction System (NOGAPS) weather forecast model (Hogan and Rosmond, 1991). Because the NOGAPS analyzed wind data are only reported at four fixed times per day (00:00, 06:00, 12:00, and 18:00 UTC), aerosol data were coupled with the wind data by matching the observation time with the closest model output time.

\section{Evaluation of MODIS Collection 5 aerosol products}

In Zhang and Reid, (2006), three major sources of uncertainties were identified in the over-ocean, C4 MODIS AOD retrievals that could affect the accuracy of satellite derived aerosol properties for aerosol data assimilation/forecasting problems: (a) lower boundary conditions, such as near surface wind, and white caps; (b) cloud contamination and cloud artifacts, and (c) uncertainties related to aerosol microphysical properties. A similar analysis was performed for the MODIS C5 over-ocean aerosol products.

A fixed near surface wind speed of $6 \mathrm{~m} \mathrm{~s}^{-1}$ is used in the current operational MODIS aerosol retrieval scheme (Remer, et al., 2005; 2008). Zhang and Reid, (2006) showed that in the MODIS $\mathrm{C} 4$ products, uncertainties in MODIS AOD $(\triangle \mathrm{AOD}$, difference between the AERONET and MODIS AOD) increase as a function of the NOGAPS near surface wind speeds $(u)$. In the MODIS C5 products, similar $\triangle$ AOD and $u$ relationships were also found for both Terra and Aqua aerosol optical depth data. Both Terra and Aqua AOD data have positive biases as a function of $u$ throughout the analysis. Also $\triangle \mathrm{AOD}$ for Terra are consistently higher than $\triangle \mathrm{AOD}$ for Aqua, indicating that the AOD values for Terra $\left(\mathrm{AOD}_{\mathrm{Terra}}\right)$ are systematically higher than the AOD values for aqua $\left(\mathrm{AOD}_{\mathrm{Aqua}}\right)$ on the multi-year global averages. This finding is consistent with what was reported by Remer et al. (2008), where a calibration difference between the Aqua and Terra MODIS instruments was indicated.

Cloud contamination and cloud artifacts are one of the long lasting issues in satellite aerosol retrievals. Positive 

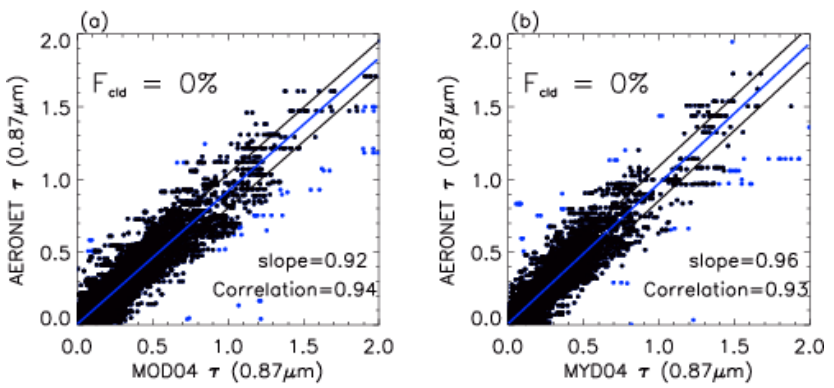

Fig. 1. Scatter plots of MODIS versus AERONET level 2.0 AOD at $0.87 \mu \mathrm{m}$ under cloud free conditions with correlation and slope of the linear regression. Blue lines are linear regression lines through the data points and the black lines show the $95 \%$ confidence interval of the blue lines. Blue dots represent the outliers that have an absolute difference between MODIS and AERONET AOD larger than 0.4. (a) for C5 Terra AOD, year 2000-2008, and (b) for C5 Aqua AOD 2002-2008.

correlations between the cloud fraction and the magnitude of overestimation in MODIS AOD were found in both $\mathrm{C} 4$ and $\mathrm{C} 5$ products. However, the underestimation of AOD under cloud free conditions shown in the $\mathrm{C} 4$ products is not found in the C5 products (Fig. 1), possibly due to either the improvements in the aerosol microphysical parameters as mentioned below, and also possibly due to the use of the level 2.0 AERONET data in the current analysis.

Zhang and Reid (2006) found that the predefined constant parameters used in aerosol models have a significant influence on aerosol retrievals, as an overestimation in AOD occurs for fine aerosols $(\eta<0.6)$ and underestimation occurs for coarse aerosols $(\eta>0.6) . \quad \eta$ is defined as the fine mode to total aerosol optical depth, and could be referred to as either the $\eta$ included in the MODIS aerosol product ( $\eta_{\text {modis }}$ ) or the AERONET $\eta\left(\eta_{\mathrm{sp}}\right)$ that was derived from the AERONET data using the a spectral de-convolution algorithm by O'Neill et al., (2003). Different from the $\mathrm{C} 4$ product, the effects of $\eta$ on MODIS retrieved AOD are much reduced in the $\mathrm{C} 5$ product. The improvements are partially due to the readjustments in the MODIS reported $\eta$ (Remer et al., 2005). Zhang and Reid (2006) compared $\eta$ values from the collocated MODIS C4 and AERONET data for moderate to high aerosol loading cases (AERONET AOD>0.2) and found the correlations of 0.69 and 0.70 , and slopes of 0.42 and 0.49 , for Aqua and Terra, respectively. Similar comparisons were made using the over-ocean MODIS C5 aerosol products with the same study period as used in Zhang and Reid (2006). The correlations between the MODIS C5 and AERONET $\eta$ are 0.67 and 0.74 , and the slopes are improved to 0.60 and 0.70 for Aqua and Terra, respectively. Note that the level 2 instead of level 1.5 AERONET data were used in this analysis and part of the improvements seen here could be due to the use of a better quality AERONET data, but the influence of the different versions of AERONET data should be small as more than a year's worth of data were used.
In summary, comparing with the C4 and C5 MODIS overocean aerosol products, the improvements in aerosol microphysics are clearly noticeable, but the biases in MODIS AOD due to surface wind effects and cloud contaminations still exist. Lastly, although the uncertainties due to the radiometric calibration could also be important (e.g. Remer et al., 2005), however, this is beyond the focus of this study and thus are not discussed.

\section{Quality check and quality assurance procedures}

As the analysis indicated, biases and uncertainties in the satellite reported AOD values are functions of observing conditions, and can be studied and systematically removed or reduced. Based on these relationships, quality assurance (QA) and empirical correction procedures were developed, evaluated and applied, and new versions of level 3 MODIS aerosol products were generated for future data assimilation studies. The QA and empirical correction procedures follow the strategies illustrated in Zhang and Reid (2006). Following improvements made to the MODIS C5 aerosol product (Remer et al., 2008), a nine-year analysis was performed and compared with the one year of analysis from Zhang and Reid (2006). Therefore, we expect the analysis from this study to be more statistically consistent.

\subsection{Quality assurance analysis}

Quality assurance steps were performed before the empirical corrections to ensure that cloud contaminated pixels and isolated retrievals were removed from the final products, and also to ensure that empirical corrections will not be biased by these retrievals. The three separate steps for this procedure include standard error checks, buddy checks, and QA flag checks.

A standard error check was performed to determine the spatial variation of the MODIS AOD values surrounding a valid retrieval. Pixels with high spatial variations of the MODIS AOD were assumed to be cloud contaminated retrievals and were removed from future analysis. This technique is used to detect retrievals near the edges of the clouds, as studies have found a correlation between MODIS AOD and cloud fraction (Leob and Manalo-Smith, 2005) that can be attributed mostly to cloud contamination and cloud artifacts (Zhang et al., 2005a). Standard error is calculated using:

$$
\mathrm{STD}_{\mathrm{error}}=\frac{\sigma}{\sqrt{N}}
$$

Where $\sigma$ is the standard deviation

$$
\sigma=\sqrt{\frac{1}{N} \sum_{i=1}^{N}\left(x_{i}-\mu\right)^{2}}
$$



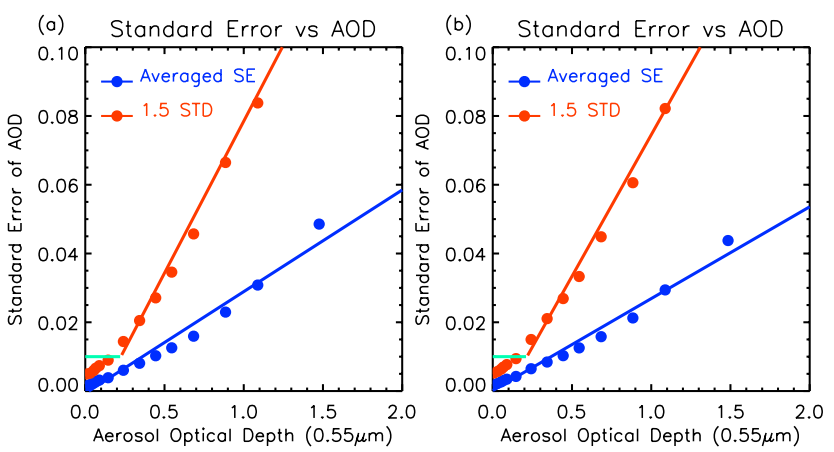

Fig. 2. Scatter plot of standard error threshold of AOD versus AOD at $0.55 \mu \mathrm{m}$. Dots represent the averaged Standard Error (blue) of AOD and the 1.5 standard deviation (red) for every 0.05 of AOD when $\mathrm{AOD}<0.5$ and 0.3 of $\mathrm{AOD}$ when $\mathrm{AOD}>0.5$. In small AOD cases, light blue lines show the cutoff of 0.01 in standard error. The blue lines and red lines (for AOD $>0.2$ only) show the linear fit of corresponding dots. (a) for C5 Aqua MODIS AOD. (b) for C5 Terra MODIS AOD.

$N$ is sample size, $x_{i}$ is each sample value, $\mu$ is the expected value. Here standard error is calculated for every $3 \times 3$ pixels around a given retrieval.

Figure $2 \mathrm{a}$ and $\mathrm{b}$ show the average standard error threshold as a function of MODIS Terra and Aqua AOD, respectively, estimated using three years (2005-2007) of level 2, C5 MODIS data. Linear relationships between the standard error and AOD were found when standard errors are greater than 0.01 while polynomial relationships were found for standard errors smaller than 0.01. For close to zero AOD values, the reported uncertainty in MODIS AOD is \pm 0.03 (Remer et al., 2005), therefore, a threshold of 0.01 in standard error is given for AOD values less than $0.178(0.195)$ to avoid removals of "good" data with low AOD values for Terra (Aqua). The linear fit of 1.5 standard deviation points serve as an upper limit for larger AOD. The relations

$$
\begin{aligned}
& \mathrm{STD}_{\text {error }}=-0.0025+0.070 \times \mathrm{AOD} \\
& \mathrm{STD}_{\text {error }}=-0.0060+0.082 \times \mathrm{AOD}
\end{aligned}
$$

represent the limits for Terra and Aqua larger AOD situations respectively. Data located above these thresholds were considered to have an unacceptable standard error and were removed.

Buddy checks were then performed to remove isolated pixels. A given pixel is removed if there are no valid retrievals among its immediate neighbors, which indicates that this isolated pixel could be located between clouds. The quality flag included in the aerosol products is utilized as a last step to filter the data. Only retrievals that are flagged as "best" and "good" data, with reported cloud fraction less than $80 \%$, were used.

\subsection{Empirical corrections}

Empirical corrections were developed using data that passed the quality assurance filters and were observed with a cloud fraction of less than $80 \%$. These corrections are aimed to reduce the biases from cloud artifacts, surface wind speed effects, and aerosol microphysics effects. The procedures for developing the empirical equations for MODIS AOD products at the $0.55 \mu \mathrm{m}$ spectrum were created for two cases: (1) low AOD case (MODIS AOD $<0.2$ ), where biases in the aerosol products are highly dependant on the lower boundary conditions, such as the near surface wind speed and cloud artifacts; and (2) high AOD case (MODIS AOD >0.2), where aerosol microphysical effects and cloud contamination are critical (Zhang and Reid, 2005). Obvious outliers were hand checked and removed, and regressions were made from all available results to generate coefficients for correction equations. The empirical correction equations were derived following Zhang and Reid (2006).

For the low AOD case $(\mathrm{AOD}<0.2)$, equations were generated as functions of near surface wind speed $(u)$ and cloud fraction $\left(F_{\text {cld }}\right)$.

$\mathrm{AOD}_{\text {new }}=\mathrm{AOD}_{\text {old }}+A-B \times u-C \times F_{\text {cld }}$

$A, B$ and $C$ are calculated separately for different values of Glint Angle $(\psi)$ with coefficients shown in Table 1. Also shown are the parameters from the C4 MODIS for comparison. Similar values for parameters B (for wind) and C (for cloud fraction) between the $\mathrm{C} 4$ and $\mathrm{C} 5$ products suggest that the impacts of wind speed and cloud fraction to the MODIS AOD retrievals for low AOD cases still exist and are similar in magnitudes to those derived for the $\mathrm{C} 4$ products.

For the high AOD case (AOD $>0.2)$, the empirical corrections were derived as functions of cloud fraction and fine mode fraction $(\eta)$. Both Zhang and Reid (2006) and this study suggest that biases in the over-ocean MODIS AOD data can be characterized by cloud fraction and $\eta$ values. Therefore, at first, the valid ranges of cloud fraction and $\eta$ were categorized into sub-sections, and the performance of the C5 MODIS AOD data was studied for each given subsection of cloud fraction, and $\eta$, and later the regression analysis was applied to estimate the parameters in the empirical correction Eq. (6). Details of the regression analysis can also be found in Zhang and Reid, (2006). The investigations of data performances as functions of influence factors are sensitive to how the observation conditions are divided. Thus, the Monte Carlo method was used to reduce the uncertainties brought in by the variation of thresholds and to generate more robust parameters. Based on the thresholds of cloud fraction $\left(F_{\mathrm{cld}}\right)$ and fine mode fraction, which ensure that the data are equally distributed in all categories of observation conditions, small random variations were introduced, and 2187 cases were computed. The comparisons with the coefficients of Eq. (6) for $\mathrm{C} 4$ and $\mathrm{C} 5$ products are shown in Table 2:

$\mathrm{AOD}_{\text {new }}=\mathrm{AOD}_{\text {old }} \times\left(A-B \times F_{\text {cld }}+C \times \eta\right)+D$ 
Table 1. Coefficients from Eq. (5) for Terra and Aqua for different ranges of Glint Angle ( $\psi)$ in Eq. (5) $\mathrm{AOD}_{\text {new }}=\mathrm{AOD}_{\mathrm{old}}+A-B \times u-$ $C \times F_{\text {cld }}$ for the MODIS C5 data. The coefficients for the MODIS C4 data are in parenthesis.

\begin{tabular}{lllll}
\hline & & $A$ & $B$ & $C$ \\
\hline \multirow{2}{*}{ Terra } & $30^{\circ}<\psi<60^{\circ}$ & $0.0184(0.05)$ & $0.0039(0.0038)$ & $0.0003(0.0003)$ \\
& $60^{\circ}<\psi<80^{\circ}$ & $0.0042(0.02)$ & $0.0017(0.0017)$ & $0.0003(0.0001)$ \\
& $\psi>80^{\circ}$ & $0.0014(0.02)$ & $0.0011(0.0007)$ & $0.0002(0.0001)$ \\
\hline \multirow{2}{*}{ Aqua } & $30^{\circ}<\psi<60^{\circ}$ & $0.0250(0.05)$ & $0.0045(0.0069)$ & $0.0003(0.0003)$ \\
& $60^{\circ}<\psi<80^{\circ}$ & $0.0109(0.03)$ & $0.0021(0.0026)$ & $0.0002(0.0000)$ \\
& $\psi>80^{\circ}$ & $0.0029(0.02)$ & $0.0004(0.0004)$ & $0.0002(0.0004)$ \\
\hline
\end{tabular}

Table 2. Coefficients for Terra and Aqua in Eq. (6) $\mathrm{AOD}_{\text {new }}=\mathrm{AOD}_{\text {old }} \times\left(A-B \times F_{\text {cld }}+C \times \eta\right)+D$ for $\mathrm{C} 5$ and $\mathrm{C} 4$ data.

\begin{tabular}{llllll}
\hline & & $A$ & $B$ & $C$ & $D$ \\
\hline \multirow{2}{*}{ Terra } & C5 & 0.863 & 0.0019 & 0.13 & $-0.028+0.00036 \times F_{\text {cld }}+0.062 \times \eta$ \\
& C4 & 0.673 & 0.0021 & 0.46 & 0.025 \\
Aqua & C5 & 0.840 & 0.0010 & 0.30 & $-0.00074-0.00014 \times F_{\text {cld }}+0.00266 \times \eta$ \\
& C4 & 0.558 & 0.0018 & 0.63 & 0.020 \\
\hline
\end{tabular}

These equations indicate that cloud fraction and $\eta$ are of critical importance as a $100 \%$ change of cloud fraction and $\eta$ could lead to a $10-20 \%$ and $10-30 \%$ change in MODIS AOD, respectively. Comparing with parameters from the $\mathrm{C} 4$ products, the impact of cloud contaminations has a similar magnitude, which is shown as parameter B in Eq. (6), in both the $\mathrm{C} 4$ and $\mathrm{C} 5$ products, yet the impact of $\eta$ is much reduced in the C5 products, as suggested by the analysis in Sect. 3. Details of the regression analysis can also be found in Zhang and Reid (2006).

\section{Validation}

Using the empirical corrections and quality assurance procedures developed in the previous section, new over-ocean AOD data sets from the MODIS C5 Terra and Aqua were generated for 2000-2008 and 2002-2008, respectively.

To evaluate the newly developed AOD data sets, intercomparisons were made using the AOD values from the new data sets against the AERONET data, as shown in Fig. 3. Figure 3 a shows a comparison of AERONET and the original MODIS Terra AOD, and Fig. $3 b$ and c show the same comparisons but with the Terra AOD after quality assurance only and the newly generated MODIS Terra AOD for nine years of data, respectively. Comparing Fig. 3a, b and c, the slope of MODIS versus AERONET AOD is corrected in the empirical correction steps and most outliers (as indicated by a red circle) are removed in the quality assurance steps. One important parameter for evaluating the quality of the new data set is the Root Mean Square Error (RMSE) of AOD between MODIS and AERONET, which is calculated using
$\mathrm{RMSE}=\sqrt{\frac{1}{n} \sum_{n}\left(\mathrm{AOD}_{\mathrm{AERONET}}-\mathrm{AOD}_{\mathrm{MODIS}}\right)^{2}}$

Table 3 lists the RMSEs between MODIS and AERONET AOD values before and after the QA and the empirical correction procedures. The overall RMSE between MODIS (Terra) and AERONET AOD decreases 34\%, from 0.092 to 0.061 , with 0.066 after quality assurance procedures and decreases $29 \%$, from 0.137 to 0.097 , in high AOD cases

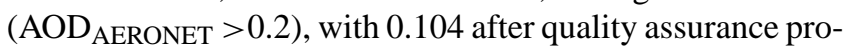
cedures. The slope of linear fit line (red line) increases from 0.78 to 0.90 to 0.98 . A threshold cloud fraction of $80 \%$ is applied for these results with a data loss of $25 \%$ after quality assurance steps and $26 \%$ after all procedures. Figure $4 \mathrm{a}$, b and c show comparisons of Aqua MODIS and AERONET AOD values before and after corrections for seven years of data. Results for Terra and Aqua are similar. The overall RMSE between Aqua and AERONET AOD decreases by $21 \%$ for all AOD cases and decreases $12 \%$ for high AOD cases. The slopes of the linear fit line increase from 0.87 to 0.93 to 0.97 , with a data loss of $23.5 \%$ after quality assurance steps and $24 \%$ after all procedures.

The empirical corrections and quality assurance procedures were also validated through the study of independent data sets that are not used in generating Eq. (5) through Eq. (6). Figure 5 is similar to Figs. 3 and 4, except when using the collocated MODIS Terra/Aqua and AERONET level 1.5 data for 2009. The AERONET level 1.5 instead of Level 2.0 data were used because the AERONET level 2.0 data are reported after yearly round instrumental calibrations (T. Eck, personal communication, 2008), and there were not enough AERONET level 2.0 data available for 2009. Again, most outliers are removed, and the slope of the MODIS and 


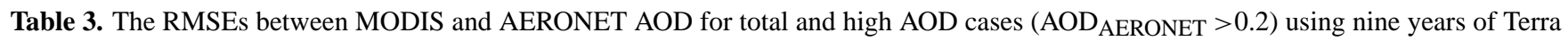
and eight years of Aqua data.

\begin{tabular}{llll}
\hline RMSEs & MODIS & After QA & After QA and the empirical correction \\
\hline Terra AOD & 0.092 & 0.066 & 0.061 \\
Terra AOD & 0.137 & 0.105 & 0.097 \\
$($ AOD & & \\
AquRONET $>0.2)$ & & & 0.069 \\
Aqua AOD & 0.087 & 0.072 & 0.106 \\
$\left(\right.$ AOD $\left._{\text {AERONET }}>0.2\right)$ & 0.121 & 0.111 & \\
\hline
\end{tabular}

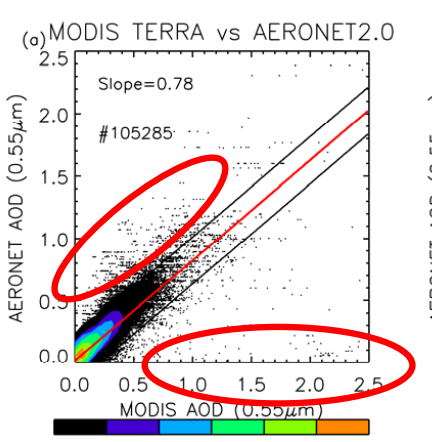

$\begin{array}{llllllll}0 & 0.0050 .01 & 0.02 & 0.05 & 0.09 & 0.16\end{array}$

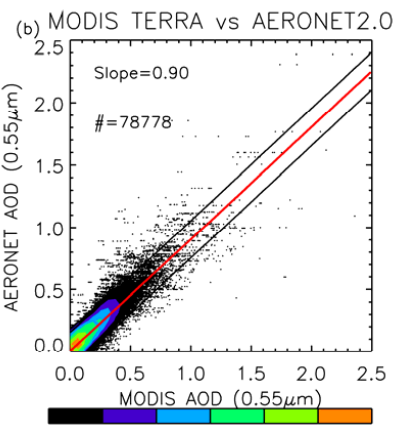

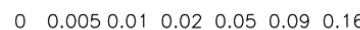

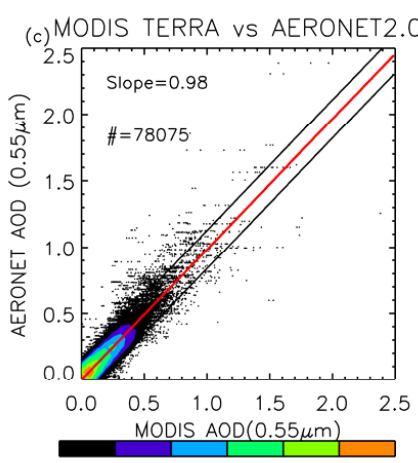

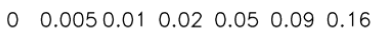

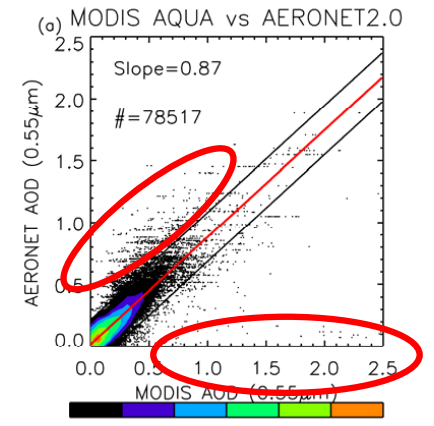

$\begin{array}{llllll}0 & 0.0050 .01 & 0.02 & 0.05 & 0.09 & 0.16\end{array}$

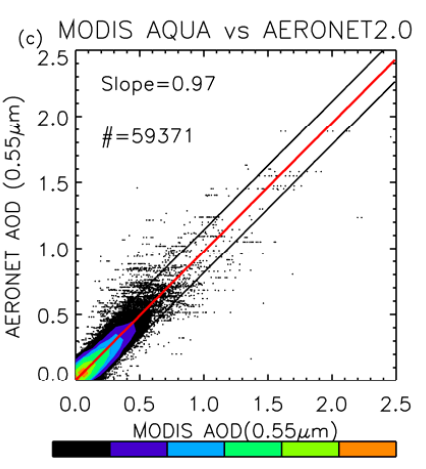

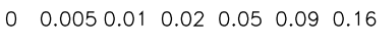

Fig. 4. Density plots of Aqua MODIS versus AERONET level 2.0 AOD at $0.55 \mu \mathrm{m}$ for 2002-2008. Color contour shows the number density of data per unit plotting area. Black indicates areas with low data density while orange indicates high data density regions. The red line is the linear regression line for all data and the black lines are the 1.0 standard deviation line of the red line. The red circles highlight the outliers were removed after the QA procedures. (a) for the MODIS C5 aerosol products. (b) for the aerosol data that passed the quality assurance filters. (c) for the newly generated level 3 MODIS AOD.

To demonstrate the changes for the newly generated data spatially, Fig. 6a-d were created by spatially averaging the AOD data in every one-degree latitude and longitude square for 2005 and 2006. Figures $6 \mathrm{a}$ and $6 \mathrm{~b}$ show the spatial plots of the original MODIS Terra C5 and the data produced in this study. The main features are similar before and after the empirical corrections and QA procedures, although 

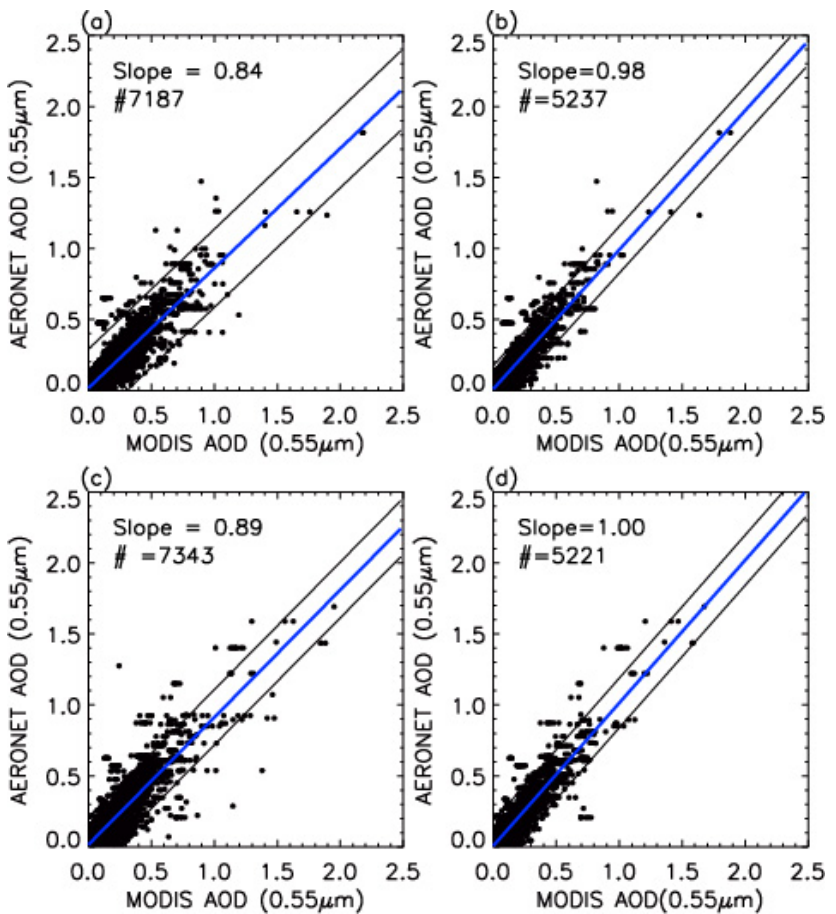

Fig. 5. Scatter plot of MODIS versus AERONET level 1.5 AOD at $0.55 \mu \mathrm{m}$ for 2009 . The blue line is the linear regression line for all data and the black lines are the 1.0 standard deviation line of the blue line. (a) for the Terra MODIS C5 aerosol products. (b) for the newly generated Terra MODIS AOD. (c) for the Aqua MODIS C5 aerosol products. (d) for the newly generated Aqua MODIS AOD.

the aerosol distribution patterns are smoother for the data produced in this study. This is because the standard-errorcheck step works as a high-pass filter, which removes the high frequency noise while maintaining the low frequency signals. A large reduction of AOD is found over the southern oceans. A high AOD (0.3-0.5) zone is located over the southern oceans in Fig. 6a, but this aerosol zone is not found in Fig. 6b, indicating that this high AOD zone might be caused by cloud contamination and thus was mostly removed by quality assurance steps (Zhang and Reid, 2006). Figure $6 \mathrm{c}$ and d show the plots similar to those in Fig. 6a and $b$, except for the Aqua aerosol products before and after empirical corrections and QA procedures. Again, the primary patterns are preserved and the suspiciously high AOD band over the southern oceans is removed, suggesting that the potential cloud contamination issue exists in both Terra and Aqua aerosol products.

For diagnostic (prognostic) purposes, the RMSE values of the MODIS AOD data were plotted as functions of the AERONET AOD (MODIS AOD) and cloud fraction for both Terra and Aqua with original (Fig. 7) and the data produced in this study (Fig. 8). Shown in Fig. 7a and c, for the AERONET AOD values smaller than 0.3, the RMSE values of the MODIS C5 Terra (Aqua) data are fluctuating (a)

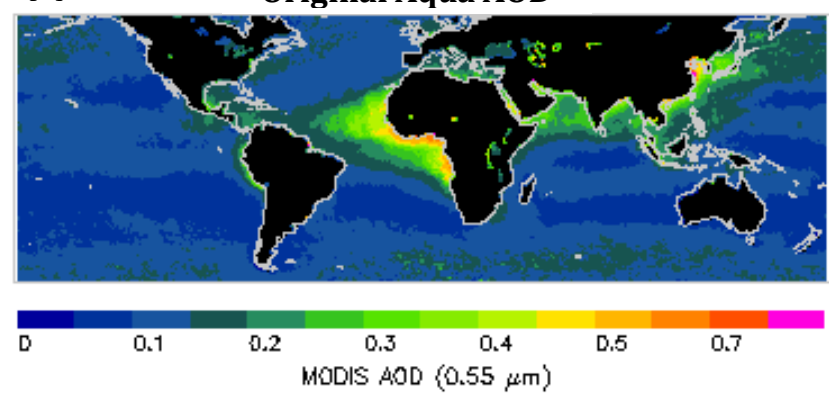

(b)

New Aqua AOD
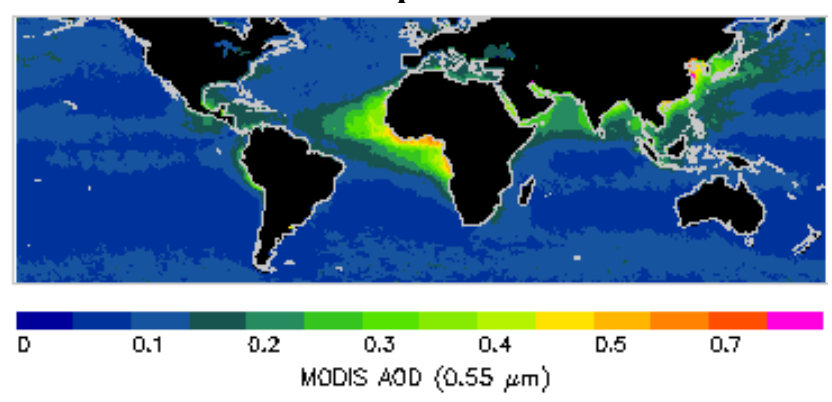

(c)
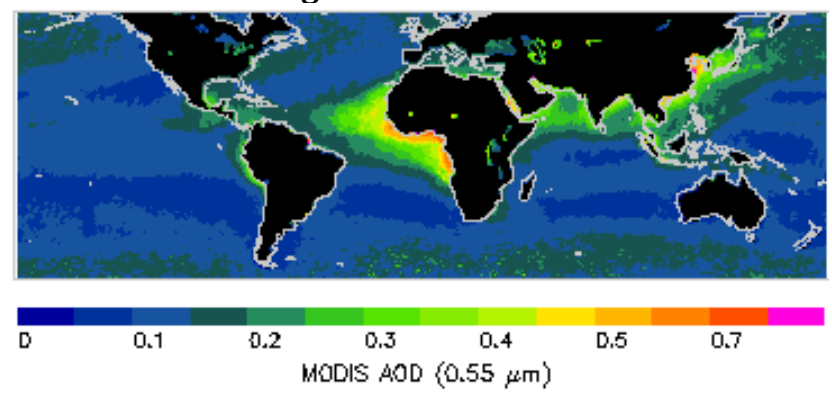

(d) New Terra AOD

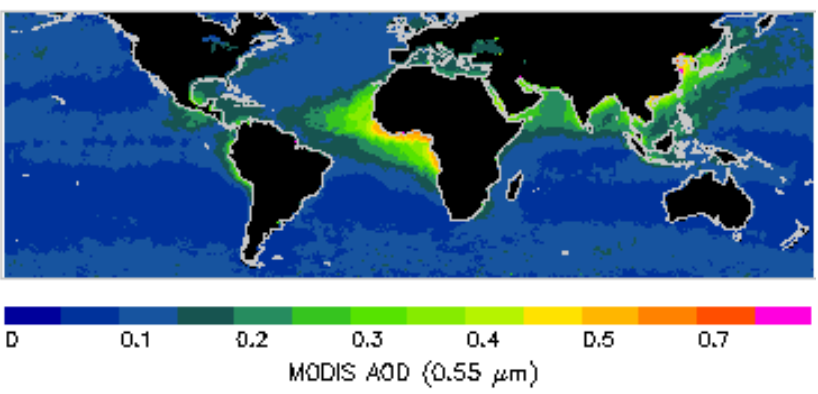

Fig. 6. Spatial distribution of AOD at $0.55 \mu \mathrm{m}$ from the MODIS C5 aerosol products. Black color represents land, blue color represents areas with low AOD loadings, and pink color indicates areas with extreme high AOD values. (a) for the original Aqua MODIS data. (b) As in (a) but for the newly generated Aqua AOD. (c) and (d) As in (a) and (b) but for Terra AOD.

around a noise floor of $0.06(0.057)$, with the noise floor values of $0.048,0.061$ and $0.086(0.046,0.063$ and 0.083$)$ for the $0-30 \%, 30-60 \%$ and $60-100 \%$ cloud fraction cases 

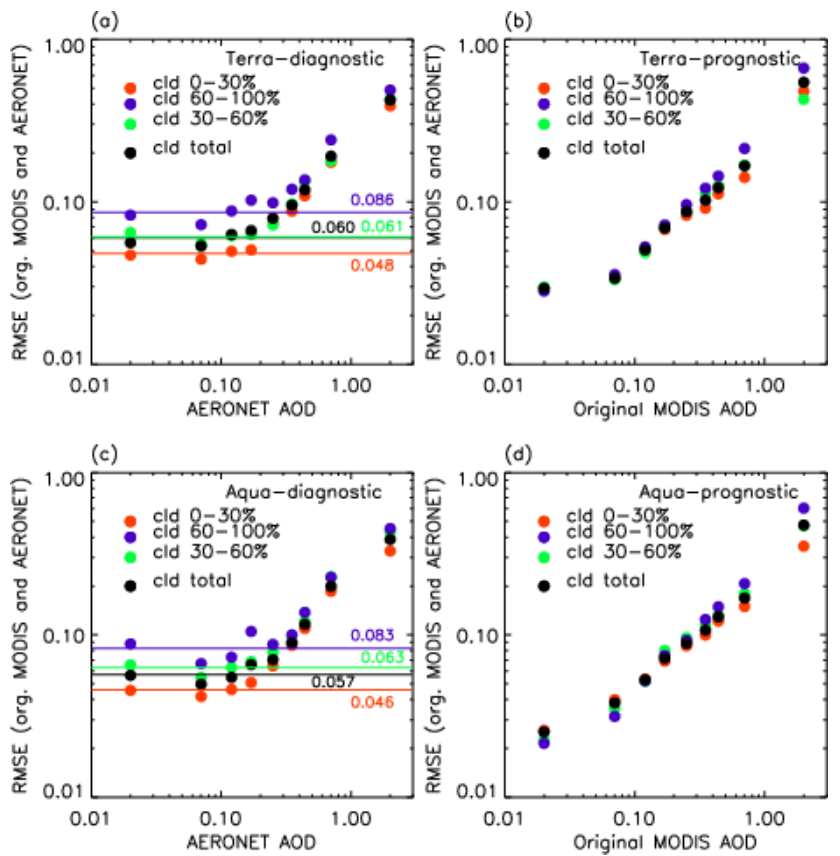

Fig. 7. RMSE of MODIS Terra and Aqua C5 AOD compared to AERONET AOD as a function of AERONET AOD and MODIS AOD. Data under different cloud fraction conditions are indicated with different colors. Red, green purple, and black represent data with cloud fraction between $0-30 \%, 30-60 \%, 60-100 \%$, and with total clouds.

respectively. For the AERONET AOD values greater than 0.3 , the second order polynomial relations were estimated between the RMSE of MODIS C5 data the AERONET AOD. Similar relations were also found by performing the prognostic analysis using the MODIS AOD instead of AERONET AOD data as shown in Fig. 7b. For all cloud ranges and AOD ranges, the RMSEs of the new MODIS data are reduced with significant reductions in noise floors (Fig. 8). The noise floors are $0.044(0.044)$ for total AOD, $0.042(0.042)$ for 0-30\% cloud, 0.047 (0.047) for 30-60\% cloud, and 0.049 (0.052) for $60-80 \%$ cloud for Terra (Aqua). The noise floor of RMSE values decrease as the percentage of cloud fraction decreases indicating that the cloud-induced uncertainties are reduced for retrievals with less cloudiness.

As discussed above, the uncertainties in satellite aerosol retrievals are highly influenced by cloud fractions, and one of the most problematic areas is the high-latitude southern oceans. For example, the averaged cloud fraction over $40^{\circ} \mathrm{S}-$ $60^{\circ} \mathrm{S}$ is $45 \%$ annually (estimated using the MOD04 cloud fraction data from 2006). And if we assume an AOD value of 0.25 (representative value for the high AOD band over southern oceans from Fig. 6), and based on Figs. 7 and 8, we estimate that over the southern oceans the MODIS AOD data in this study have $30-35 \%$ of RMSE reduction compared with the original MODIS AOD.
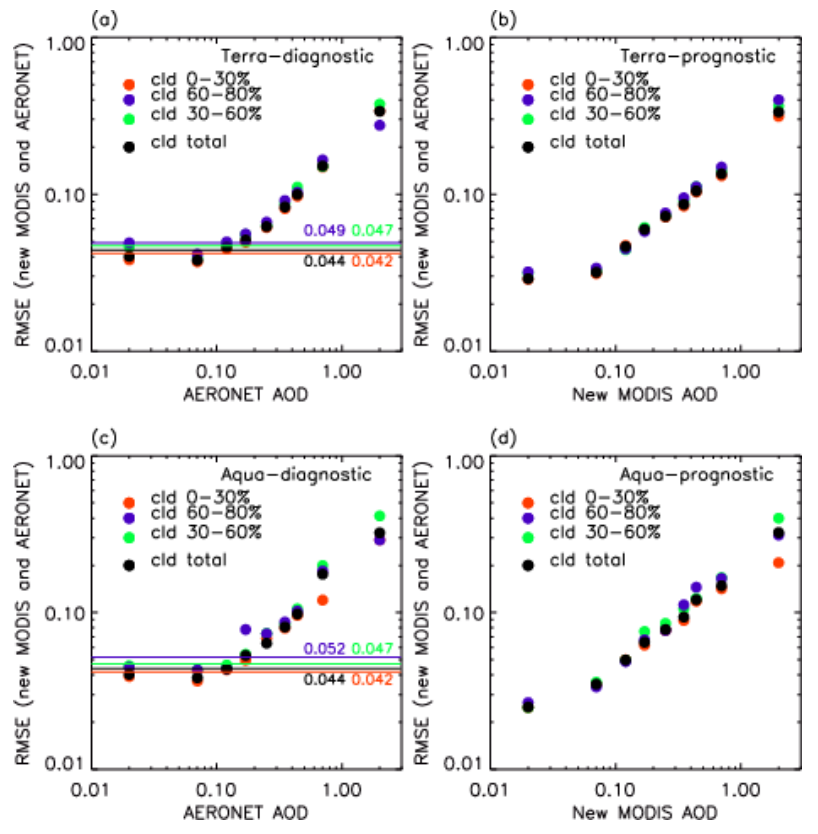

Fig. 8. RMSE of newly generated MODIS Terra and Aqua AOD comparing to AERONET AOD as a function of AERONET AOD and MODIS AOD. Data under different cloud fraction conditions are indicated with different colors. Red, green purple, and black represent data with cloud fraction between $0-30 \%, 30-60 \%, 60$ $80 \%$, and with total clouds.

We also examined the yearly performance of the data produced in this study. Evaluated against the AERONET data, the differences between the RMSEs for MODIS AOD before and after corrections were estimated from 2000 to 2008 for Terra and from 2002 to 2008 for Aqua and for three AOD regimes: MODIS $\mathrm{AOD}<0.2$; MODIS $\mathrm{AOD}>0.2$; and all available AOD retrievals. The percentages of improvements were calculated for all three AOD ranges, as shown in Fig. 9. In all AOD regimes the RMSEs from the new products are consistently smaller than the original products for all available years, with the percentages of improvements ranging from 15 to $40 \%$ for all available AOD retrievals.

\section{Conclusions and discussions}

This study evaluated uncertainties of satellite over-ocean aerosol products by comparing satellite data with groundbased AERONET data and by using ten years of Terra MODIS C5 data and eight years of Aqua MODIS C5 data. Uncertainties were examined as functions of near surface wind speed, cloud fraction, and aerosol microphysics in order to develop empirical correction procedures. Strong relationships were found between uncertainties in the MODIS C5 aerosol products and three potential uncertainty sources: near surface wind speed, cloud fraction and microphysics. This is similar to what was shown in the MODIS C4 aerosol 

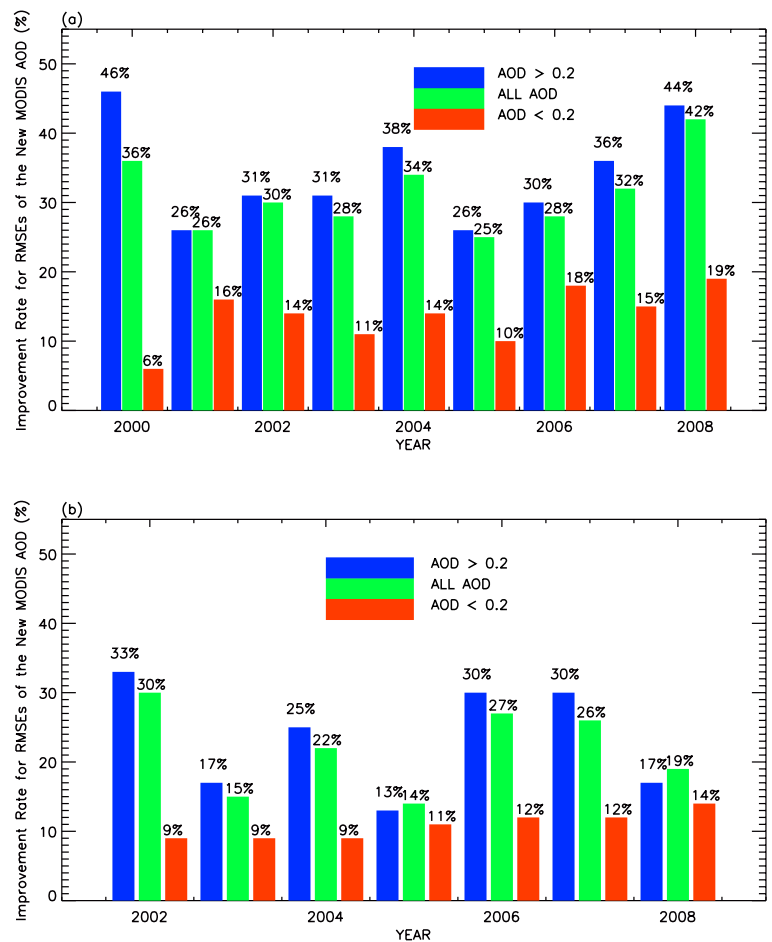

Fig. 9. The percentages of improvements for the RMSEs between MODIS AOD and AERONET AOD at $0.55 \mu \mathrm{m}$ before and after corrections, for all data (green), data with MODIS AOD greater than 0.2 (blue), and data with MODIS AOD smaller than 0.2 (red). (a) for Terra 2000-2008, (b) for Aqua 2002-2008.

products (Zhang and Reid, 2006). Yet the improvements in MODIS $\eta$ (fine mode AOD fraction), and the effects of aerosol microphysics to the retrieved MODIS AOD are noticeable in the over-ocean MODIS C5 aerosol product. Quality assurance steps were also established to remove data samples with possible cloud contamination. New products with less uncertainty were generated as level 3 over-ocean MODIS aerosol products for future data assimilation and model use. This study suggests that, after the QA and empirical corrections, the RMSE of the over-ocean operational MODIS C5 aerosol products is improved by more than 20 $30 \%$ for Terra and more than $10-20 \%$ for Aqua globally, and by $30-35 \%$ over the southern oceans. This study will be extended to over-land areas by including products from other retrievals, such as the Deep Blue products (Hsu et al., 2006).

Acknowledgements. This research was funded by the Office of Naval Research Code 322, the Office of Naval Research Young Investigator Program, and the NASA Interdisciplinary Science Program. Yingxi Shi is supported by the NASA Earth and Space Science Fellowship (NESSF) Program. We acknowledge and appreciate the AERONET program and their contributing principal investigators and their staff for establishing and maintaining the coastal sites used in this investigation. We thank Lorraine Remer for her constructive suggestions. We thank William Lahoz and an anonymous reviewer for their thoughtful comments.
Edited by: W. Lahoz

\section{References}

Hogan, T. F., and Rosmond, T. E.: The Description of the Navy Operational Global Atmospheric Prediction Systems Spectral Forecast Model, Mon. Weather Rev., 119(8), 1786-1815, 1991.

Holben, B. N., Eck, T. F., Slutsker, I., Tanré, D., Buis, J. P., Setzer, A., Vermote, E., Reagan, J. A., Kaufman, Y. J., Nakajima, T., Lavenu, F., Jankowiak, I., and Smirnov, A.: A ERONETA Federated Instrument Network and Data Archive for Aerosol Characterization, Remote Sens. Environ. 66, 1-16, 1998.

Hsu, N. C., Tsay, S., King, M. D., and Herman, J. R.: Deep Blue Retrievals of Asian Aerosol Properties During ACE-Asia, IEEE transactions on geoscience and remote sensing, ISSN 0196-2892 CODEN IGRSD2., 44(1), 3180-3195, 2006.

Kahn, R. A., Nelson, D. L., Garay, M. J., Levy, R. C., Bull, M. A., Diner, D. J., Martonchik, J. V., Paradise, S. R., Hansen, E. G., and Remer, L. A.: MISR Aerosol Product Attributes and Statistical Comparisons with MODIS, Transactions on Geoscience and Remote Sensing, IEEE T. Geosci. Remote, 47(12), 4095-4114, doi:10.1109/TGRS.2009.2023115, 2009.

Liu, L. and Mishchenko, M. I.: Toward unified satellite climatology of aerosol properties: Direct comparisons of advanced level 2 aerosol products, J. Quant. Spectrosc. Ra. Transf., 109(14), 2376-2385, doi:10.1016/j.jqsrt.2008.05.003, 2008.

Loeb, N. G. and Manalo-Smith, N: Top-of-Atmosphere Direct Radiative Effect of Aerosols over Global Oceans from Merged CERES and MODIS Observations, J. Climate, 18, 3506-3526, 2005.

O’Neill, N. T., Dubovik, O., and Eck, T. F.: A modified Angstrom Coefficient for The Characterization of Sub-micron Aerosols, App. Opt., 40(15), 2368-2374, 2001.

O'Neill, N. T., Eck, T. F., Smirnov, A., Holben, B. N., and Thulasiraman, S.: Spectral Discrimination of Coarse and Fine Mode Optical Depth, J. Geophys. Res., 108(D17), 4559, doi:10.1029/2002JD002975, 2003.

Remer, L. A., Kaufman, Y. J., Tanré, D., Matoo, S., Chu, D. A., Martins, J. V., Li, R.-R., Ichoku, C., Levy, R. C., Kieidman, R. G., Eck, T. F., Vermote, E., and Holben, B. N.: The MODIS Aerosol Algorithm, Products, and Validation, J. Atmos. Sci., 62(4), 947-973, doi:10.1175/JAS3385.1, 2005.

Remer, L. A., Kleidman, R. G., Levy, R. C., Kaufman, Y. J., Tanré, D., Mattoo, S., Martins, J. V., Ichoku, C., Koren, I., Yu, H., and Holben, B. N.: Global aerosol climatology from the MODIS satellite sensors. J. Geophys. Res., 113, D14S07, doi:10.1029/2007JD009661, 2008.

Zhang, J. and Reid, J. S.: MODIS Aerosol Product Analysis for Data Assimilation: Assessment of Over-Ocean level 2 Aerosol Optical Thickness Retrievals, J. Geophys. Res., 111. D22207, doi:10.1029/2005JD006898, 2006.

Zhang, J. and Reid, J. S.: A System for Operational Aerosol Optical Depth Data Assimilation over Global Oceans, J. Geophys. Res., 113, D10208, doi:10.1029/2007JD009065, 2008.

Zhang, J., Reid, J. S., and Holben, B. N.: An analysis of potential cloud artifacts in MODIS over ocean aerosol optical thickness products, Geophys. Res. Lett., 32, L15803, doi:10.1029/2005GL023254, 2005. 